\title{
Influenza A(H7N9) Virus Antibody Responses in Survivors 1 Year after Infection, China, 2017
}

\author{
Mai-Juan Ma, ${ }^{1}$ Cheng Liu, ${ }^{1}$ Meng-Na Wu, Teng Zhao, Guo-Lin Wang, Yang Yang, \\ Hong-Jing Gu, Peng-Wei Cui, Yuan-Yuan Pang, Ya-Yun Tan, Hui Hang, Bao Lin, \\ Jiang-Chun Qin, Li-Qun Fang, Wu-Chun Cao, Li-Ling Chen
}

\begin{abstract}
Avian influenza $A(H 7 N 9)$ virus has caused 5 epidemic waves in China since its emergence in 2013. We investigated the dynamic changes of antibody response to this virus over 1 year postinfection in 25 patients in Suzhou City, Jiangsu Province, China, who had laboratory-confirmed infections during the fifth epidemic wave, October 1, 2016-February 14,2017 . Most survivors had relatively robust antibody responses that decreased but remained detectable at 1 year. Antibody response was variable; several survivors had low or undetectable antibody titers. Hemagglutination inhibition titer was $\geq 1: 40$ for $<40 \%$ of the survivors. Measured in vitro in infected mice, hemagglutination inhibition titer predicted serum protective ability. Our findings provide a helpful serologic guideline for identifying subclinical infections and for developing effective vaccines and therapeutics to counter H7N9 virus infections.
\end{abstract}

7 he novel avian influenza A(H7N9) virus has caused 5 1 epidemic waves in China since its emergence in 2013. As of September 20, 2017, a total of 1,561 human cases were reported, with a case fatality rate of $\approx 39 \%$ (1). In particular, a substantial increase of 758 human cases was reported during the fifth epidemic, compared with the earlier 4 (1). Highly pathogenic H7N9 viruses emerged and infected both humans (1) and poultry (2) during the fifth epidemic. In addition, $\mathrm{H} 7 \mathrm{~N} 9$ virus readily obtained the $627 \mathrm{~K}$ or $701 \mathrm{~N}$ mutation in its polymerase basic (PB) 2 segment upon replication in ferrets (3), suggesting that the virus has pandemic potential and continues to pose grave risks to public health.

The H7N9 subtype has the highest risk score among the 12 novel influenza A viruses evaluated by the Centers

Author affiliations: Beijing Institute of Microbiology and Epidemiology, Beijing, China (M.-J. Ma, M.-N. Wu, T. Zhao, G.-L. Wang, H.-J. Gu, L.-Q. Fang, W.-C. Cao); University of Florida, Gainesville, Florida, USA (Y. Yang); Suzhou Municipal Center for Disease Control and Prevention, Suzhou, China (C. Liu, P.-W. Cui, Y.-Y. Pang, Y.-Y. Tan, H. Hang, B. Lin, J.-C. Qin, L.-L. Chen)

DOI: https://doi.org/10.3201/eid2404.171995 for Disease Control and Prevention using the Influenza Risk Assessment Tool and is characterized as posing moderateto high-potential pandemic risk (4). Apart from the ongoing monitoring of virologic and molecular characteristics of H7N9 viruses in poultry and humans, studies on the dynamic changes of antibody response in survivors are critical for serologic diagnosis, population-based seroepidemiologic surveys, and vaccine design and development. A few studies have investigated virus-specific antibody kinetics to the H7N9 virus in patients and their relationship with disease severity (5-7), but these studies were restricted to antibodies measured in the acute and convalescent phases. No followup studies have been done on dynamic antibody changes in survivors who had recovered from the disease. As a result, the long-term serologic response to H7N9 virus infections is poorly understood and remains of clinical interest. In our study, we investigated the long-term dynamic changes in antibody response in H7N9 survivors identified during the fifth epidemic in China and examined the relationship between antibody responses and clinical characteristics.

\section{Materials and Methods}

\section{Study Design and Participants}

During the fifth epidemic wave of the H7N9 virus (October 1, 2016-February 14, 2017), we conducted a longitudinal serologic survey on a cohort patient who had recovered from the disease in Suzhou, Jiangsu Province, China. We screened 34 patients who had laboratory-confirmed cases and were $>18$ years of age when they were discharged from the hospital (Figure 1). We enrolled 25 of these patients in our study after obtaining informed consent and prospectively followed them at $\approx 100,200$, and 300 days after symptom onset (Figure 1). In addition, we enrolled 10 control subjects who live in an area without known H7N9 virus detections, denied close contact with live poultry or live bird markets during the previous 12 months, and had no known diseases or conditions that would reduce their immune response.

${ }^{1}$ These authors contributed equally to this article. 


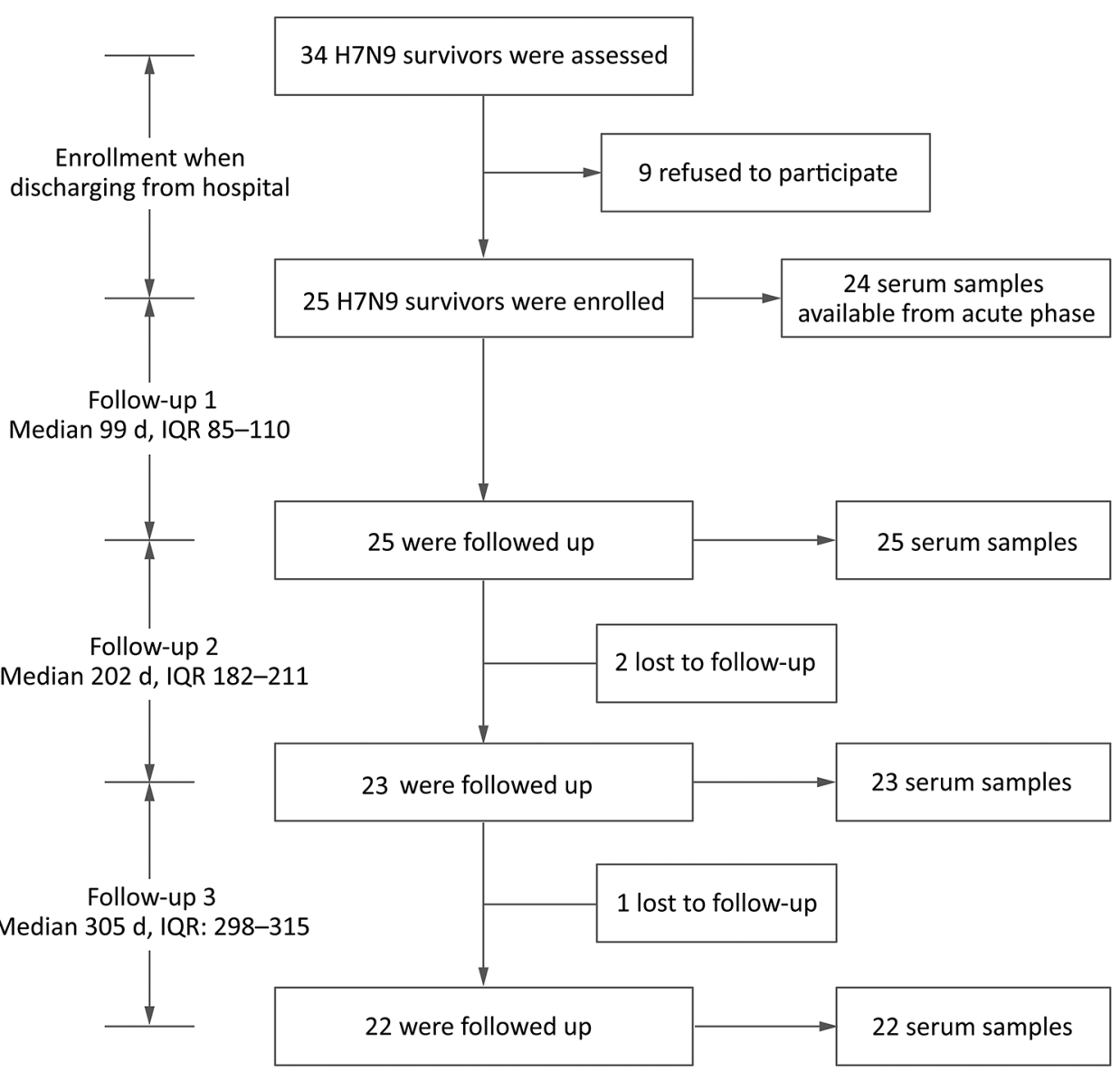

Figure 1. Schematic outline for study of influenza A(H7N9) virus antibody responses in survivors 1 year after infection, China, 2017. IQR, interquartile range.

We obtained written informed consent from all participants before conducting interviews and sample collection. The study protocol was approved by the Institutional Review Boards of Beijing Institute of Microbiology and Epidemiology and Suzhou Municipal Center for Disease Control and Prevention. The study was also approved by the Animal Care and Use Committee at the Academy of Military Medical Sciences.

\section{Sampling and Data Collection}

At patient enrollment, we used a comprehensive questionnaire to collect information about patients' demographic and clinical characteristics, history of exposure to poultry, and history of seasonal influenza vaccination. We included archived acute- or convalescent-phase serum samples from the participants in our study. At each of the 3 follow-up visits, we asked each participant to provide a $5-\mathrm{mL}$ blood sample. We used a shorter questionnaire to collect information about demographic characteristics, recent history of exposure to poultry, and experience of influenza-like illness.

\section{Serologic Testing}

We measured serum hemagglutination inhibition (HI) antibody ( 8 ) by the HI assay; neutralizing antibody by the microneutralization ( $\mathrm{MN}$ ) assay (9); neuraminidase inhibition (NI) antibody by the enzyme-linked lectin assay (ELLA) (10); and IgG or IgA antibodies by ELISA (5). For HI, NI, and MN detection, we applied 2-fold serial dilutions of serum from 1:10 to $1: 280$. We defined the HI titer as the reciprocal of the highest serum dilution that completely inhibited hemagglutination; the NI titer as the reciprocal of highest serum dilution that exhibited $50 \%$ inhibition concentration $\left(\mathrm{IC}_{50}\right)$; and the $\mathrm{MN}$ titer as the reciprocal of the highest serum dilution that yielded $\geq 50 \%$ neutralization. For final titers $<1: 10$ we assigned a value of 1:5 (seronegative). For IgG and IgA detection, we tested serum samples at a starting dilution of 1:50 with 2-fold serial dilutions to $1: 12,800$. The endpoint titer was the highest dilution giving an optical density at least twice that of background. The final titers $<1: 50$ we assigned a value of 1:25. We used a human H7N9 isolate (A/Jiangsu/ Wuxi05/2013) for the HI and MN assays. We used a genetic reassortant $\mathrm{H} 6 \mathrm{~N} 9$ virus, which contains the hemagglutinin gene of $\mathrm{H} 6 \mathrm{~N} 1$ virus $\mathrm{A} /$ Taiwan/1/2013, the neuraminidase gene of $\mathrm{H} 7 \mathrm{~N} 9$ virus $\mathrm{A} / \mathrm{Anhui} / 1 / 2013$, and other internal genes of A/Puerto Rico/8/1934 H1N1, for ELLA. We used currently circulating human seasonal viruses (A/Shanghai/SWL1970/2015/H1N1 and A/Switzerland/ 
9715293/2013/H3N2) to examine the serum samples for cross-reacting antibodies with $\mathrm{HI}$ assay.

We defined a seroprotective threshold as an HI, NI, or MN antibody titer of 40. A titer of $\geq 1: 40$ of HI, NI, or MN antibody has been shown to protect against seasonal influenza viruses (11-13) and is considered protective against H7N9 infection in humans, but has not been proven so. There is no established correlation of protection for $\operatorname{IgG}$ and IgA titers for influenza virus infection, but any detectable antibody level is deemed protective. We set the cutoff value for $\operatorname{IgG}$ titer to $1: 400$ because the mean titer among control serum samples was 1:350.

\section{Human Serum Passive Transfer and H7N9 Infection of Mice}

We obtained 42 female 4-week-old specific pathogen-free BALB/c mice from the Laboratory Animal Center, Academy of Military Medical Sciences, Beijing, China. The mice weighed $13.3 \pm 0.9 \mathrm{~g}$. We injected 3 mice per group intravenously with $40 \mu \mathrm{L}$ of human serum (2-fold serial HI titration ranged from 1:5 to $1: 1,280) 12$ hours before injecting them intranasally with $20 \mu \mathrm{L}$ of $10 \times 50 \%$ lethal dose of H7N9 virus. We gave an equal volume of healthy donor serum or phosphate-buffered saline to control mice. We observed the mice daily for signs of disease for $\leq 3$ days. We conducted all work with the H7N9 virus in the Biosafety Level 3 laboratory of the State Key Laboratory of Pathogen and Biosecurity.

\section{Antibody in Serum and Virus Titers in Lungs of Mice}

We collected blood from the mice 12 hours after injection with human serum. Because we transferred only $40 \mu \mathrm{L}$ serum to the mice and there was $\approx 30$-fold dilution of $>1 \mathrm{~mL}$ blood, we expected the HI titer in mice to be undetectable. Therefore, we used the ELISA method to measure IgG titers. To obtain virus titers, we harvested the lungs of 3 mice at 3 days after virus infection and homogenized them into $1.5 \mathrm{~mL}$ of Dulbecco's Modified Eagle Medium using a manual homogenizer. We aliquoted lung homogenates and kept them at $-80^{\circ} \mathrm{C}$. We determined the viral titer using the tissue culture infectious dosage on MDCK cells.

\section{Statistical Analysis}

We analyzed the antibody titers with $\log _{10}$-transformed geometric means and 95\% CIs. We calculated the proportion of antibody titers equal to or greater than seroprotective threshold (HI, NI, and MN) or limit of detection and associated $95 \%$ CI. We used Mann-Whitney U test for testing the differences in antibody titers and $\chi^{2}$ test and Fisher exact test for testing the differences in proportion of antibody titers above thresholds. All statistical tests were 2 -sided with a significance level of 0.05 . We conducted all statistical analyses using GraphPad Prism software (GraphPad Software, Inc., La Jolla, CA, USA).

\section{Results}

During October 1, 2016-February 14, 2017, we enrolled in our study 25 laboratory-confirmed H7N9 survivors from Suzhou, Jiangsu Province, China (Figure 1). Among these survivors, 17 were men and 8 were women; the median age was 59 years (range 49.5-66.5 years) (Table 1). All patients required hospitalization at 1-12 days after symptom onset. Most of the patients had severe illness and were admitted to the intensive care unit (ICU). Patients remained in the ICU for 7-30 days. Clinical symptoms included fever, cough, sore throat, fatigue, myalgia, chills, and dyspnea (Table 2). All patients received oseltamivir, and 21 received glucocorticoid for treatment. Laboratory tests at hospital admission showed that some patients had abnormal hepatic function. Most patients had low to medium viral load (online Technical Appendix Table 1, https://wwwnc.cdc.gov/EID/ article/24/4/17-1995-Techapp1.pdf). In addition, H7N9 viruses isolated from 11/25 patients were of low pathogenicity and belonged to the Yangtze River Delta hemagglutinin lineages (online Technical Appendix Table 1). The radiographic findings included pneumonia, increased markings, fuzzy patch lesions, and patch effusion shadows in lungs (online Technical Appendix Table 2).

Table 3 shows the proportion of survivors with antibody titers equal to or greater than the seroprotective threshold (1:40 for HI, NI, and MN) or the minimum detection limit (1:400 for IgG and 1:50 for IgA) at each time point. Counting from the day of symptom onset, $>90 \%$ of survivors had an HI titer $\geq 1: 40$ on day 100 . This proportion reached $82.6 \%$ on day 200 but decreased to $36.4 \%$ on day 300 . The overall patterns of the NI antibody titers were similar to the HI antibody titers, except that $63.6 \%$ of survivors had an NI titer $\geq 1: 40$ on day 300 . Unlike the $\mathrm{HI}$ and NI antibody titers, the proportion of seroprotective MN $(\approx 86 \%)$ and $\operatorname{IgG}(100 \%)$ titers remained steady over time. For IgA antibody titers, the seroprotective proportion decreased from $96 \%$ on day 100 to $\approx 60 \%$ on day 300 , an absolute reduction of $\geq 30 \%$.

The geometric mean titers (GMTs) of antibodies were plotted by the time points in Figure 2. Overall, $\approx 300$ days after symptom onset, HI and NI GMTs substantially declined and were lower than the seroprotective threshold of 1:40 and the GMTs in the acute phase (Figure 2, panels A and B). In contrast, the MN GMTs increased over time, peaked on day 200 , and then declined by day 300 , yet remained considerably above the GMTs in the acute phase and the seroprotective threshold of 1:40 (Figure 2, panel C). Although we observed no substantial difference in GMTs across 3 follow-up time points, the MN GMTs on day 200 were relatively high, suggesting a possible delayed response after infection. IgG and IgA decreased gradually from day 100 to day 300 but remained higher than the limit of detection (Figure 2, panel D). However, IgG GMTs on 
Table 1. Clinical characteristics of influenza A(H7N9) virus survivors, China, 2017*

\begin{tabular}{|c|c|c|c|c|c|c|}
\hline $\begin{array}{l}\text { Patient } \\
\text { no. }\end{array}$ & Age, y/sex & Symptoms & $\begin{array}{l}\text { Days to } \\
\text { admissiont }\end{array}$ & Hospitalization, d & ICU, d & $\begin{array}{l}\text { Disease } \\
\text { severity }\end{array}$ \\
\hline 1 & $89 / \mathrm{M}$ & $\begin{array}{c}\text { Fever, cough, sore throat, fatigue, } \\
\text { myalgia }\end{array}$ & 6 & 18 & 16 & Severe \\
\hline 2 & $32 / \mathrm{M}$ & Fever, cough, sore throat & 12 & 22 & 12 & Severe \\
\hline 3 & $41 / \mathrm{F}$ & Fever, cough, sore throat, fatigue & 8 & 19 & 14 & Severe \\
\hline 4 & $83 / \mathrm{M}$ & Fever, cough, fatigue & 4 & 11 & 9 & Severe \\
\hline 5 & $62 / \mathrm{M}$ & Fever, cough & 7 & 12 & 12 & Severe \\
\hline 6 & $71 / \mathrm{M}$ & Fever, cough & 9 & 18 & 13 & Severe \\
\hline 7 & $63 / F$ & Fever, cough, fatigue & 9 & 16 & 10 & Severe \\
\hline 8 & $54 / F$ & Fever, cough, sore throat & 7 & 14 & 9 & Severe \\
\hline 9 & $54 / F$ & Fever, cough, fatigue & 7 & 17 & 17 & Mild \\
\hline 10 & $60 / F$ & Fever, cough, fatigue, chills & 7 & 28 & 23 & Severe \\
\hline 11 & 28/F & Fever, cough, fatigue & 7 & 16 & 11 & Severe \\
\hline 12 & $63 / \mathrm{M}$ & Fever, cough & 6 & 14 & 14 & Severe \\
\hline 13 & $65 / \mathrm{M}$ & Fever, cough & 5 & 19 & 0 & Severe \\
\hline 14 & $35 / \mathrm{M}$ & Fever, cough, sore throat, fatigue & 6 & 12 & 12 & Severe \\
\hline 15 & $39 / F$ & Fever, cough & 7 & 19 & 19 & Severe \\
\hline 16 & $57 / \mathrm{M}$ & Fever, cough & 10 & 17 & 17 & Severe \\
\hline 17 & $75 / \mathrm{M}$ & Fever, cough, fatigue & 9 & 22 & 13 & Severe \\
\hline 18 & $58 / \mathrm{M}$ & Fever, cough, myalgia & 5 & 15 & 8 & Mild \\
\hline 19 & $54 / F$ & Fever, fatigue, myalgia & 5 & 11 & 11 & Severe \\
\hline 20 & $59 / \mathrm{M}$ & Fever, cough & 5 & 21 & 7 & Severe \\
\hline 21 & $68 / \mathrm{M}$ & Fever, cough, dyspnea & 5 & 30 & 30 & Severe \\
\hline 22 & $59 / \mathrm{M}$ & Fever, cough & 7 & 22 & 22 & Severe \\
\hline 23 & 45/M & Fever, cough & 1 & 13 & 9 & Severe \\
\hline 24 & $71 / \mathrm{M}$ & Fever, cough & 2 & 73 & NA & Severe \\
\hline 25 & $64 / \mathrm{M}$ & Fever, cough, sore throat & 6 & 13 & 11 & Mild \\
\hline
\end{tabular}

ICU, intensive care unit; NA, not available.

†After symptom onset.

day 200 and day 300 were substantially higher than the $\operatorname{IgG}$ GMTs in the acute phase, whereas the IgA GMTs on day 200 and day 300 were similar to those in the acute phase. There were no detectable antibodies to the H7N9 virus in the control subjects, but GMT was 283.3 (titer ranged from 1:200 to 1:800) for IgG, suggesting a possible cross-reactivity between the $\mathrm{H} 7 \mathrm{~N} 9$ virus and other subtypes.

Approximately 300 days after symptom onset, nearly all survivors had a $\geq 4$-fold decline in the HI titer compared with the titer on day 100 , and 14 survivors had HI titers $<1: 40$ (Tables 4, 5; Figure 2, panel A). Among these 14 survivors, 2 (patients 1 and 2) maintained low titers (1:10) throughout the study period, but 2 others (patients 4 and 25 ) had undetectable titers around day 300 . The other 10 survivors had titers of 1:20. Twenty-one survivors had a $\geq 4$-fold decrease of the NI titer $\approx 300$ days after symptom onset, and 8 survivors (patients 1, 2, 4, 8, 11, 14, 22, and 25 ) had titers $<1: 40$ (Tables 4,5 ). Among these 8 survivors, the titer of patient 2 declined to seronegative on day 349 , and others had titers $\leq 1: 20$ (Tables 4, 5; Figure 2, panel B). In contrast, the majority of survivors had a $\geq 2$-fold increase in MN titer ( 9 survivors) or maintained $\mathrm{MN}$ titer (8 survivors) on day 200 in comparison to day 100 after symptom onset, followed by a decrease or a maintenance on day 300 (Figure 2, panel C; Tables 4 and 5). However, 6 survivors (patients 1, 2, 4, 8, 21, and 25) maintained low titers over the study period (Tables 4, 5; Figure 2, panel C), but none of them became seronegative. Although most of the survivors had a $\geq 4$-fold decline in IgG titer over time, all survivors maintained detectable antibody titers $\geq 1: 400$ (Tables 4, 5; Figure 2, panel D). However, the overall response of IgA antibody was relatively weak, and 9 survivors (patients 1, 3, 4, 15, 18, 19, 21, 22, and 25) already had undetectable titer on day 200 (Tables 4, 5; Figure 2, panel E).

To further assess the physiologic contribution of the magnitude of the $\mathrm{HI}$ antibody titers, we transferred $40 \mu \mathrm{L}$ convalescent-phase serum from individual patients to mice (online Technical Appendix Table 3). IgG titers in the serum samples of recipient mice correlated well with $\mathrm{IgG}$, $\mathrm{HI}$, and $\mathrm{MN}$ titers in the human serum samples, but we observed a better correlation for IgG titer in the human samples (Figure 3, panels A-D). Mouse IgG titers in the serum samples at the time of challenge correlated inversely with virus titers in the lung samples, confirming the importance of neutralizing antibodies assessed in laboratory analysis in virus clearance (Figure 3, panels E, F). These results also suggest that an $\mathrm{IgG}$ titer of $>1: 160$ was required to reduce virus titers by $0.5 \log _{10}$ in infected mice. Assuming that these numbers can be extrapolated to patients, transferring $40 \mu \mathrm{L}$ of serum to a $13-\mathrm{g}$ mouse is equivalent to transferring $210 \mathrm{~mL}$ of serum to a $70-\mathrm{kg}$ patient (calculated per kilogram), thereby providing a potential guideline for its use in clinical settings.

The different types of antibody measures are significantly correlated with each other; we observed higher correlation between HI and NI and between NI and IgG at 
Table 2. Underlying disease, complications, and treatment of influenza A(H7N9) virus survivors, China, 2017*

\begin{tabular}{|c|c|c|c|c|c|c|c|}
\hline $\begin{array}{l}\text { Patient } \\
\text { no. }\end{array}$ & $\begin{array}{l}\text { Underlying } \\
\text { disease }\end{array}$ & Complications & $\begin{array}{l}\text { Oxygen } \\
\text { therapy }\end{array}$ & $\begin{array}{l}\text { Mechanical } \\
\text { ventilation }\end{array}$ & $\begin{array}{c}\text { Days to antiviral } \\
\text { treatment } \dagger\end{array}$ & Oseltamivir & Glucocorticoid \\
\hline 1 & HTN, DM & ARDS, RF & Yes & No & 6 & Yes & Yes \\
\hline 2 & No & ARDS, RF & Yes & No & 13 & Yes & Yes \\
\hline 3 & No & ARDS, RF & Yes & No & 8 & Yes & Yes \\
\hline 4 & COPD, HTN & No & Yes & No & 6 & Yes & Yes \\
\hline 5 & HTN & ARDS, RF & Yes & No & 7 & Yes & Yes \\
\hline 6 & HTN, DM & ARDS, HI & Yes & No & 14 & Yes & No \\
\hline 7 & No & ARDS & Yes & No & 9 & Yes & Yes \\
\hline 8 & No & No & Yes & No & 7 & Yes & Yes \\
\hline 9 & No & No & Yes & No & 9 & Yes & Yes \\
\hline 10 & No & ARDS, RF, HI, RI & Yes & Yes & 11 & Yes & Yes \\
\hline 11 & No & $\mathrm{HI}$ & Yes & No & 7 & Yes & Yes \\
\hline 12 & No & No & Yes & No & 8 & Yes & No \\
\hline 13 & No & No & Yes & No & 8 & Yes & Yes \\
\hline 14 & No & No & Yes & No & 6 & Yes & Yes \\
\hline 15 & No & $\mathrm{HI}$ & Yes & No & 7 & Yes & Yes \\
\hline 16 & No & RF & Yes & No & 13 & Yes & No \\
\hline 17 & No & ARDS & Yes & No & 9 & Yes & Yes \\
\hline 18 & No & No & Yes & No & 13 & Yes & Yes \\
\hline 19 & No & $\mathrm{RF}, \mathrm{HI}$ & Yes & No & 5 & Yes & Yes \\
\hline 20 & HTN & ARDS, RF, HI & Yes & Yes & 11 & Yes & Yes \\
\hline 21 & HTN, DM, HL & ARDS, RF, HI & Yes & Yes & 5 & Yes & Yes \\
\hline 22 & HTN & ARDS, RF, HI & Yes & No & 7 & Yes & Yes \\
\hline 23 & HTN & No & Yes & No & 6 & Yes & NA \\
\hline 24 & NA & NA & Yes & NA & 1 & Yes & NA \\
\hline 25 & $\mathrm{CHB}$ & $\mathrm{HI}$ & Yes & No & 9 & Yes & Yes \\
\hline
\end{tabular}

$\mathrm{R}^{2}>0.5$ (online Technical Appendix Figure 1). We found no correlation between antibodies to the H7N9 virus and $\mathrm{HI}$ antibodies against seasonal $\mathrm{H} 1 \mathrm{~N} 1$ and $\mathrm{H} 3 \mathrm{~N} 2$ viruses $(p>0.05)$ (online Technical Appendix Figure 2), indicating that there is no heterologous boost of antibodies against $\mathrm{H} 7$ by $\mathrm{H} 3$ or $\mathrm{H} 1$ hemagglutinin. The antibody responses did not vary by patient age, sex, presence of underlying conditions, time in ICU, ventilation, or disease severity.

\section{Discussion}

In our study, antibodies to H7N9 virus waned over time, but most survivors maintained detectable antibody titers $\approx 1$ year after infection. However, $>60 \%$ of survivors had an $\mathrm{HI}$ titer $<1: 40$, which is potentially not seroprotective, $\approx 300$ days after infection. Antibody responses were highly variable in survivors, and a few of them had weak antibody responses or had quickly waning antibody titers that were undetectable $\approx 1$ year after infection despite their severity of infection. We also identified a threshold of IgG titer that was crucial to virus clearance in the animal model and could be useful in clinical settings.

$\mathrm{HI}$ antibodies induced by natural infection with the 2009 pandemic H1N1 virus persist at constant high titer $(>1: 40$ ) for a minimum of 15 months (14). Additionally, the $\mathrm{HI}$ antibody against the $\mathrm{H} 5 \mathrm{~N} 1$ virus infection is reported to last even longer, at a stable titer $(\geq 1: 40)$ for nearly 5 years, although only a few survivors have been studied (15). In contrast, our study shows that only $36.4 \%$ of H7N9 survivors had HI titers $\geq 1: 40$ at $\approx 1$ year after infection, although most survivors had detectable HI antibody titers. On the other hand, we observed relatively high MN antibody titers persisting over time in survivors, and these levels were sufficient to predict protection, based on the protection extrapolated from seasonal influenza. If we assume that $\mathrm{MN}$ antibody is truly a better correlate of protection than $\mathrm{HI}$ antibody and a titer of $>1: 40$ is sufficient for protection, we could anticipate that most H7N9 survivors would remain protected against the $\mathrm{H} 7 \mathrm{~N} 9$ virus $\geq 1$ year after infection.

Table 3. Proportion of influenza A(H7N9) virus survivors with titers at seroprotective levels at acute phase of infection and 3 follow-up points after infection, China, $2017^{*}$

\begin{tabular}{lcccc}
\hline & \multicolumn{5}{c}{ \% Patients $(95 \%$ Cl) } \\
\cline { 2 - 5 } Antibody & Acute phase & Follow-up visit 1 & Follow-up visit 2 & Follow-up visit 3 \\
\hline $\mathrm{HI}$ & $54.5(32.2-75.6)$ & $92.0(74.0-99.0)$ & $82.6(61.2-95.0)$ & $36.4(17.2-59.3)$ \\
$\mathrm{NI}$ & $50.0(28.2-71.8)$ & $96.0(79.6-99.9)$ & $91.3(72.0-98.9)$ & $63.6(40.7-82.8)$ \\
$\mathrm{MN}$ & $22.7(7.8-45.4)$ & $88.0(68.8-97.5)$ & $87.0(66.4-97.2)$ & $86.4(65.1-97.1)$ \\
$\mathrm{IgG}$ & $45.5(24.4-67.8)$ & $100(86.3-100)$ & $100(85.2-100)$ & $100(84.6-100)$ \\
IgA & $54.5(32.2-75.6)$ & $96.0(79.6-99.9)$ & $60.9(38.5-80.3)$ & $59.1(36.4-79.3)$ \\
\hline
\end{tabular}

*Seroprotective levels for $\mathrm{HI}, \mathrm{NI}$, and $\mathrm{MN}$ titers, $\geq 1: 40$; Ig $\geq 1: 400$; or $\operatorname{lgA} \geq 1: 50$. $\mathrm{HI}$, hemagglutination inhibition; MN, microneutralization; $\mathrm{NI}$, neuraminidase inhibition. 

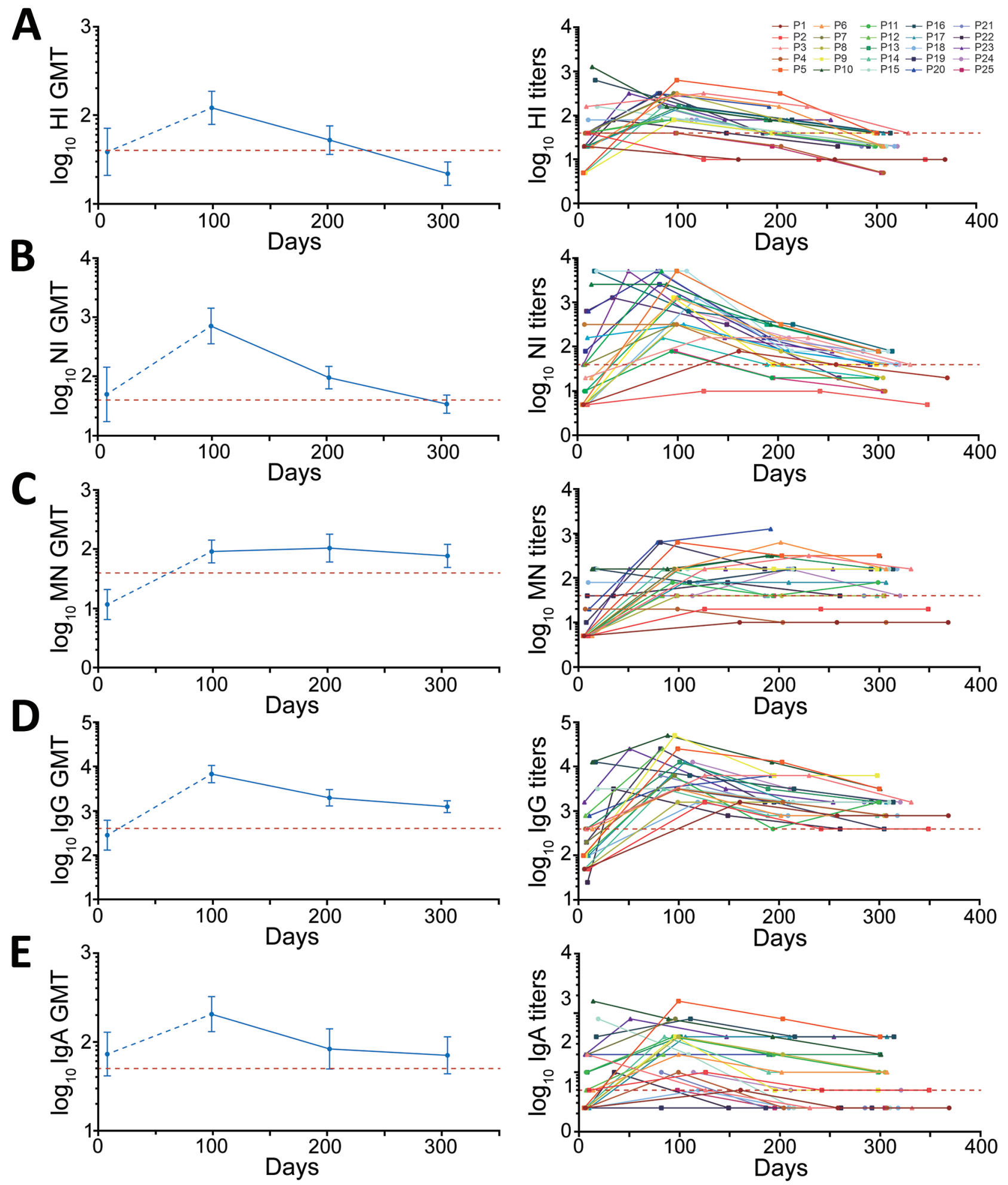

Figure 2. GMTs (left) and individual titers (right) of antibodies to influenza $A(H 7 N 9)$ virus in serum samples collected from survivors, China, 2017: A) HI, B) NI, C) MN, D) IgG, and E) IgA. Red dashed line indicates threshold for seroprotective titer (HI, $\mathrm{NI}$, and $\mathrm{MN}=1: 40)$ or limited detection titer ( $\lg G=1: 400 ; \operatorname{lgA}=1: 50)$. Error bars indicate $95 \% \mathrm{Cls}$. GMT, geometric mean titer; HI, hemagglutination inhibition; MN, microneutralization; NI, neuraminidase inhibition; P, patient. 
Table 4. Antibody titers in survivors of influenza A(H7N9) during the acute phase and at 3 follow-up points, China, 2017*

\begin{tabular}{|c|c|c|c|c|}
\hline \multirow[b]{2}{*}{ Patient no. } & \multicolumn{4}{|c|}{$\mathrm{HI} / \mathrm{NI} / \mathrm{MN} / \mathrm{lgG} / \mathrm{lgA}$ titers } \\
\hline & Acute phase & Follow-up visit 1 & Follow-up visit 2 & Follow-up visit 3 \\
\hline 1 & $20 / 5 / 5 / 50 / 25$ & 10/80/10/1600/50 & $10 / 40 / 10 / 800 / 25$ & $10 / 20 / 10 / 800 / 25$ \\
\hline 2 & $20 / 5 / 5 / 50 / 50$ & $10 / 10 / 20 / 1600 / 100$ & $10 / 10 / 20 / 400 / 50$ & $10 / 5 / 20 / 400 / 50$ \\
\hline 3 & $160 / 20 / 5 / 400 / 200$ & $320 / 160 / 160 / 6400 / 50$ & 160/160/320/6400/25 & 40/40/160/1600/25 \\
\hline 4 & 40/320/20/400/25 & 40/320/20/3200/100 & 20/40/10/1600/25 & $5 / 10 / 10 / 800 / 25$ \\
\hline 5 & $5 / 5 / 5 / 100 / 25$ & $640 / 5120 / 640 / 25600 / 1600$ & $320 / 320 / 320 / 12800 / 800$ & $40 / 80 / 320 / 3200 / 400$ \\
\hline 6 & 20/20/5/400/50 & $320 / 1280 / 160 / 3200 / 200$ & $160 / 160 / 640 / 800 / 100$ & 20/40/160/800/100 \\
\hline 7 & $40 / 40 / 5 / 200 / 200$ & $320 / 320 / 160 / 6400 / 800$ & NA & NA \\
\hline 8 & $40 / 5 / 5 / 50 / 25$ & $320 / 320 / 40 / 1600 / 400$ & $80 / 80 / 40 / 1600 / 200$ & 20/20/40/800/100 \\
\hline 9 & $5 / 5 / 5 / 100 / 25$ & $80 / 1280 / 160 / 51200 / 400$ & 40/40/160/6400/50 & $40 / 40 / 160 / 6400 / 50$ \\
\hline 10 & $1280 / 2560 / 160 / 12800 / 1600$ & $160 / 2560 / 160 / 51200 / 800$ & 80/320/320/12800/400 & $40 / 80 / 320 / 3200 / 200$ \\
\hline 11 & $40 / 10 / 5 / 100 / 100$ & 80/80/80/6400/400 & $40 / 20 / 40 / 400 / 200$ & 20/20/80/1600/100 \\
\hline 12 & $40 / 40 / 5 / 800 / 50$ & $80 / 5120 / 40 / 25600 / 200$ & NA & NA \\
\hline 13 & $20 / 10 / 5 / 400 / 100$ & $160 / 1280 / 160 / 12800 / 400$ & $80 / 320 / 320 / 3200 / 200$ & $40 / 80 / 160 / 1600 / 200$ \\
\hline 14 & $5 / 5 / 5 / 50 / 25$ & $160 / 160 / 160 / 3200 / 400$ & $40 / 40 / 40 / 800 / 100$ & 20/20/40/800/100 \\
\hline 15 & 160/5120/160/3200/800 & $80 / 5120 / 160 / 3200 / 200$ & $40 / 80 / 160 / 1600 / 25$ & 20/80/160/1600/25 \\
\hline 16 & $640 / 5120 / 160 / 12800 / 400$ & $160 / 640 / 80 / 6400 / 800$ & 80/320/160/3200/400 & $40 / 80 / 160 / 1600 / 400$ \\
\hline 17 & $20 / 160 / 5 / 100 / 25$ & $160 / 320 / 80 / 12800 / 400$ & $80 / 80 / 80 / 1600 / 400$ & $40 / 40 / 80 / 1600 / 400$ \\
\hline 18 & $80 / 5 / 80 / 100 / 25$ & $80 / 1280 / 80 / 1600 / 50$ & 40/80/160/800/25 & 20/40/160/800/25 \\
\hline 19 & $40 / 80 / 10 / 200 / 25$ & $320 / 2560 / 640 / 25600 / 25$ & $40 / 160 / 160 / 1600 / 25$ & 20/40/160/1600/25 \\
\hline 20 & $40 / 640 / 20 / 800 / 200$ & $320 / 5120 / 640 / 3200 / 200$ & $160 / 160 / 1280 / 6400 / 200$ & NA \\
\hline 21 & NA & $160 / 5120 / 40 / 6400 / 100$ & $40 / 160 / 40 / 1600 / 25$ & 20/80/40/1600/25 \\
\hline 22 & $20 / 640 / 40 / 25 / 25$ & $80 / 1280 / 40 / 3200 / 100$ & $40 / 320 / 80 / 800 / 25$ & 20/20/40/400/25 \\
\hline 23 & $20 / 40 / 5 / 1600 / 200$ & $320 / 5120 / 160 / 25600 / 800$ & $80 / 160 / 160 / 3200 / 400$ & $80 / 80 / 160 / 1600 / 400$ \\
\hline 24 & NA & $80 / 640 / 40 / 12800 / 100$ & $40 / 160 / 160 / 3200 / 50$ & 20/40/40/1600/50 \\
\hline 25 & NA & 40/80/40/3200/50 & 20/20/40/1600/25 & $5 / 10 / 40 / 400 / 25$ \\
\hline
\end{tabular}

It has been observed that antibody responses in infections with H5N1 or 2009 pandemic H1N1 virus in which patients had mild or no symptoms waned faster than those in patients with severe influenza disease and decreased below the threshold of positivity within 1 year $(16,17)$. Of all reported H7N9 cases, $<10 \%$ were asymptomatic or mild (18-20), and our study included only 3 mildly symptomatic patients (patients 9, 18, and $25)$. These 3 patients maintained detectable NI, MN, and $\mathrm{IgG}$ antibodies, but patient 25 became seronegative for HI antibodies and IgA on or around day 305 after symptom onset. Meanwhile, several severely ill

\begin{tabular}{|c|c|c|}
\hline \multirow[b]{2}{*}{ Patient no. } & \multicolumn{2}{|c|}{ Change, -fold, $\mathrm{HI} / \mathrm{NI} / \mathrm{MN} / \operatorname{lgG} / \operatorname{lgA}$} \\
\hline & Follow-up visit 2 vs. follow-up visit 1 & Follow-up visit 3 vs. follow-up visit 2 \\
\hline 1 & $1 / 0.5 / 1 / 0.5 / 0.5$ & $1 / 0.5 / 1 / 1 / 1$ \\
\hline 2 & $1 / 1 / 1 / 0.25 / 0.5$ & $1 / 0.5 / 1 / 1 / 1$ \\
\hline 3 & $0.5 / 1 / 2 / 1 / 0.5$ & $0.25 / 0.25 / 0.5 / 0.25 / 1$ \\
\hline 4 & 0.5/0.13/0.5/0.5/0.25 & $0.25 / 0.25 / 1 / 0.5 / 1$ \\
\hline 5 & 0.5/0.06/0.5/0.5/0.5 & $0.13 / 0.25 / 1 / 0.25 / 0.5$ \\
\hline 6 & $0.5 / 0.13 / 4 / 0.25 / 0.5$ & $0.13 / 0.25 / 0.25 / 1 / 1$ \\
\hline 7 & NA & NA \\
\hline 8 & $0.25 / 0.25 / 1 / 1 / 0.5$ & $0.25 / 0.25 / 1 / 0.5 / 0.5$ \\
\hline 9 & $0.5 / 0.03 / 1 / 0.13 / 0.13$ & $1 / 1 / 1 / 1 / 1$ \\
\hline 10 & $0.5 / 0.13 / 2 / 0.25 / 0.5$ & $0.5 / 0.25 / 1 / 0.25 / 0.5$ \\
\hline 11 & 0.5/0.25/0.5/0.06/0.5 & $0.5 / 1 / 2 / 4 / 0.5$ \\
\hline 12 & NA & NA \\
\hline 13 & $0.5 / 0.25 / 2 / 0.25 / 0.5$ & $0.5 / 0.25 / 0.5 / 0.5 / 1$ \\
\hline 14 & $0.25 / 0.25 / 0.25 / 0.25 / 0.25$ & $0.5 / 0.5 / 1 / 1 / 1$ \\
\hline 15 & $0.5 / 0.02 / 1 / 0.5 / 0.125$ & $0.5 / 1 / 1 / 1 / 1$ \\
\hline 16 & $0.5 / 0.5 / 2 / 0.5 / 0.5$ & $0.5 / 0.25 / 1 / 0.5 / 1$ \\
\hline 17 & $0.5 / 0.25 / 1 / 0.13 / 1$ & $0.5 / 0.5 / 1 / 1 / 1$ \\
\hline 18 & $0.5 / 0.06 / 2 / 0.5 / 0.5$ & $0.5 / 0.5 / 1 / 1 / 1$ \\
\hline 19 & $0.13 / 0.06 / 0.25 / 0.06 / 1$ & $0.5 / 0.25 / 1 / 1 / 1$ \\
\hline 20 & $0.5 / 0.03 / 2 / 2 / 1$ & NA \\
\hline 21 & $0.25 / 0.03 / 1 / 0.25 / 0.25$ & $0.5 / 0.5 / 1 / 1 / 1$ \\
\hline 22 & $0.5 / 0.25 / 2 / 0.25 / 0.25$ & $0.5 / 0.06 / 0.5 / 0.5 / 1$ \\
\hline 23 & $0.25 / 0.03 / 1 / 0.13 / 0.5$ & $1 / 0.5 / 1 / 0.5 / 1$ \\
\hline 24 & $0.5 / 0.25 / 4 / 0.25 / 0.5$ & $0.5 / 0.25 / 0.25 / 0.5 / 1$ \\
\hline 25 & $0.5 / 0.25 / 1 / 0.5 / 0.5$ & $0.25 / 0.5 / 1 / 0.25 / 1$ \\
\hline
\end{tabular}



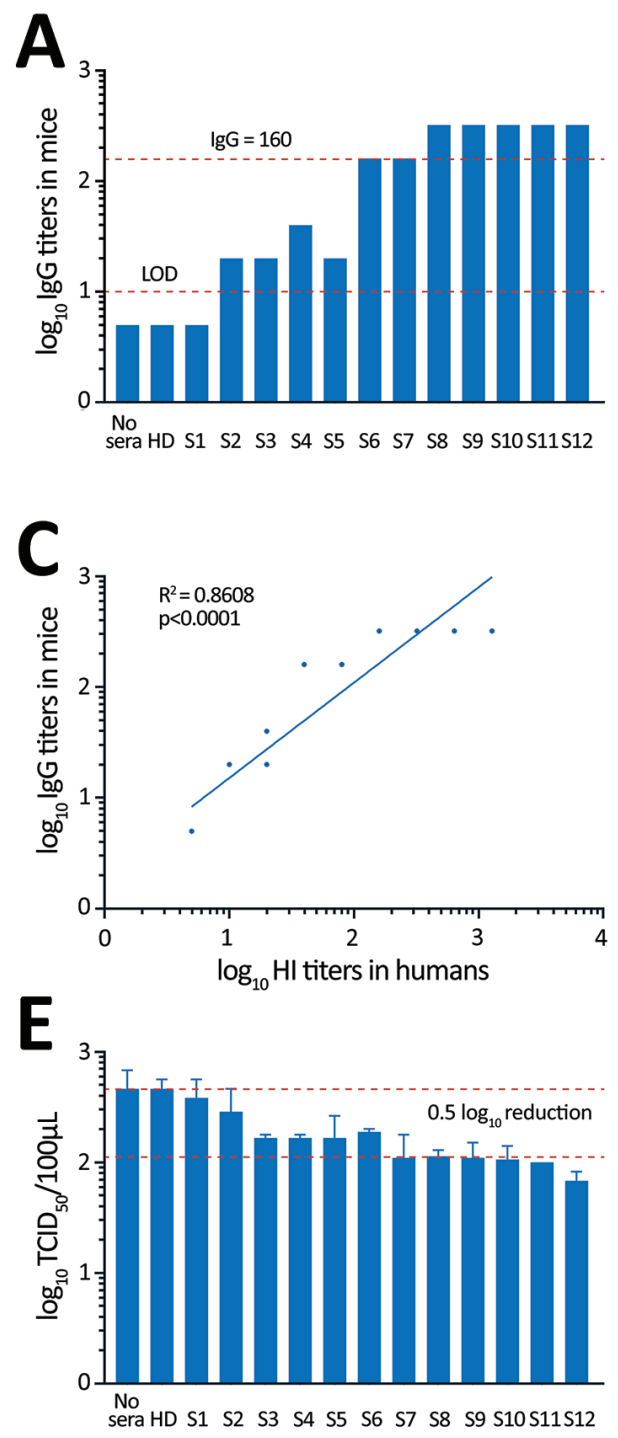
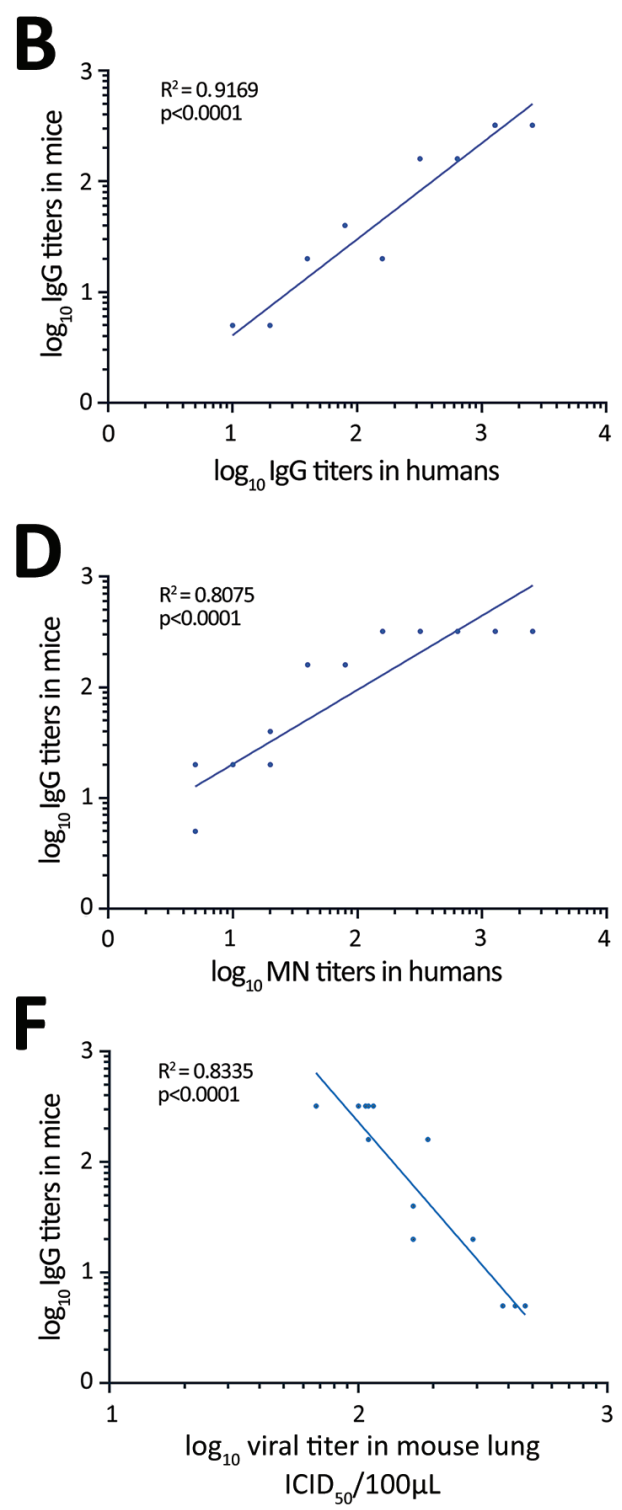

Figure 3. Testing of convalescent-phase serum transfer as potential protection against influenza $A(H 7 N 9)$ virus infection. Mice received $40 \mu \mathrm{L}$ of patient serum intravenously 12 hours before $\mathrm{H} 7 \mathrm{~N} 9$ virus infection.

A) IgG titers from mouse serum samples collected $1 \mathrm{~h}$ before infection.

B-D) Relationships between IgG, $\mathrm{HI}$, and $\mathrm{MN}$ titers in human serum and IgG titer in mouse recipients of transferred serum.

E) Virus titers in homogenized mouse lungs at day 3 after infection (mean \pm SE). F) Relationship between IgG titer in mouse serum samples and viral titers in mouse lung samples. $\mathrm{HD}$, healthy donor; $\mathrm{HI}$, hemagglutination inhibition; LOD, limit of detection; MN, microneutralization; S, serum; $\mathrm{TCID}_{50}, 50 \%$ tissue culture infectious dose. patients had relatively weak antibody responses 100 days after symptom onset; in particular, patients 1,2 , and 4 either maintained low antibody titers over time or became seronegative at $\approx 1$ year after symptom onset. Therefore, there was no clear association between disease severity and antibody response. Nevertheless, most patients in our study had severe symptoms, and so the findings may not be representative of mild cases or asymptomatic infections.

Previous seroepidemiological studies have identified the subclinical infections among both occupationally exposed workers and the general population, but the results varied (21-29). Similar to the problems with H5N1 infections in humans (30), the serologic threshold titer to recognize subclinical infections of the $\mathrm{H} 7 \mathrm{~N} 9$ virus is not yet established, which leads to difficulty in estimating the seroprevalence of subclinical infections. A major problem in identifying such a serologic threshold for seropositivity is the insufficient immunogenicity of the H7 hemagglutinin (31-34). Our results show that HI, NI, $\operatorname{IgG}$, and IgA antibodies declined substantially over time. In particular, for $\mathrm{HI}$ antibody, $>60 \%$ of survivors had a titer $<1: 40$, and 2 of them became negative at $\approx 1$ year after infection. Given the low magnitude in HI antibody response, the true incidence of $\mathrm{H} 7 \mathrm{~N} 9$ infection is likely to be underestimated if a titer of $>1: 40$ is used as the serologic threshold for the HI assay in seroepidemiological studies. In our study, the level of MN antibody titer was relatively stable over time and correlated well with other types of antibodies; therefore, the MN antibody could be a more useful indicator than HI for determining the incidence of infection. 
Convalescent plasma therapy has been considered as a treatment option for new and emerging infectious diseases for which effective drugs and vaccines are not readily available. Although the anti-influenza A virus drug oseltamivir appeared to be useful for the treatment of H7N9 infection, the $\approx 40 \%$ mortality rate still remains a challenge for clinical treatment, especially for severe cases who visit a hospital days past onset of their symptoms. Previous studies have shown that convalescent plasma treatment reduced the mortality rate of severe 2009 pandemic H1N1 infection (35) and benefited patients with severe H5N1 or H7N9 infections $(36,37)$. Our results indicate that, despite substantially decreased $\mathrm{HI}$ antibody titers over time, most of the survivors still had a titer $>1: 40 \approx 200$ days after infection, and high antibody titers are likely for other antibodies from survivors' serum. The experimental results from our model using mice suggest that transferring $210 \mathrm{~mL}$ of serum with $\mathrm{HI}$ titer $\geq 1: 80$ to a $70-\mathrm{kg}$ patient is a possible guideline for clinical treatment.

Our study had some limitations. First, our results need to be validated with larger numbers of survivors. We have thus far included 25 survivors, $\approx 3 \%$ of all reported H7N9 survivors in China. The small sample size limited our ability to analyze the antibody response stratified by patient age, sex, underlying condition, or disease severity. Second, we could not collect blood samples more frequently from the patients, especially between acute phase and $\approx 100$ days after infection, which could have provided a more complete picture about the dynamics of antibody responses. Finally, we did not study the virus-specific memory T- and B-cell response because of constraints in logistics. Whether there are correlations between cellular immune responses and antibody responses needs further investigation.

In conclusion, our findings contribute to the understanding of individual immune responses to H7N9 virus infection and of population-based immunity in regions where H7N9 virus outbreaks have occurred. Our study provides a useful serologic guideline for developing effective vaccines and therapies to counter $\mathrm{H} 7 \mathrm{~N} 9$ virus infections.

\section{Acknowledgments}

We thank all patients for their participation in the study and the staff of the local Centers for Disease Control and Prevention whose collaboration made this study possible.

This study was supported by the National Natural Science Foundation of China (81773494, 81402730, and 81621005);

Beijing Scientific and Technology Nova Program (Z171100001117088); China Mega-Project on Infectious Disease Prevention (2017ZX10303401-006); Suzhou Key Technology on Major and Infectious Diseases Prevention and Control (GWZX201502); and Suzhou Medical Key Subject (SZXK201516).

\section{About the Author}

Dr. Ma is a scientist at Beijing Institute of Microbiology and Epidemiology, Beijing, China. His research interests focus on molecular epidemiology and seroepidemiology of zoonotic influenza virus and zoonotic transmission of influenza between species.

\section{References}

1. Food and Agriculture Organization of the United Nations. H7N9 situation update. 2017 [cited 2018 Jan 31]. http://www.fao.org/ag/ againfo/programmes/en/empres/h7n9/situation_update.html

2. World Organisation for Animal Health. OIE situation report for avian influenza. 2017 [cited 2017 May 9]. http://www.oie.int/ fileadmin/Home/eng/Animal_Health_in_the_World/docs/pdf/ OIE_AI_situation_report/OIE_SituationReport_AI_6_ 8May2017.pdf

3. Shi J, Deng G, Kong H, Gu C, Ma S, Yin X, et al. H7N9 virulent mutants detected in chickens in China pose an increased threat to humans. Cell Res. 2017;27:1409-21. http://dx.doi.org/10.1038/ cr.2017.129

4. Centers for Disease Control and Prevention. Influenza risk assessment tool (IRAT). 2017 [cited 2018 Jan 31].

https://www.cdc.gov/flu/pandemic-resources/national-strategy/ risk-assessment.htm

5. Guo L, Zhang X, Ren L, Yu X, Chen L, Zhou H, et al. Human antibody responses to avian influenza A(H7N9) virus, 2013. Emerg Infect Dis. 2014;20:192-200. http://dx.doi.org/10.3201/ eid2002.131094

6. Zhang A, Huang Y, Tian D, Lau EH, Wan Y, Liu X, et al. Kinetics of serological responses in influenza A(H7N9)-infected patients correlate with clinical outcome in China, 2013. Euro Surveill. 2013;18:20657. http://dx.doi.org/10.2807/1560-7917. ES2013.18.50.20657

7. Huang R, Zhang L, Gu Q, Zhou YH, Hao Y, Zhang K, et al. Profiles of acute cytokine and antibody responses in patients infected with avian influenza A H7N9. PLoS One. 2014;9:e101788. http://dx.doi.org/10.1371/journal.pone.0101788

8. World Health Organization. Serological detection of avian influenza $\mathrm{A}(\mathrm{H} 7 \mathrm{~N} 9)$ virus infections by modified horse red blood cells haemagglutination-inhibition assay. 2013 [cited 2013 Dec 5]. $\mathrm{http} / / / \mathrm{www} . w h o . i n t /$ influenza/gisrs_laboratory/cnic_serological diagnosis_hai_a_h7n9_20131220.pdf

9. Rowe T, Abernathy RA, Hu-Primmer J, Thompson WW, Lu X, Lim W, et al. Detection of antibody to avian influenza A (H5N1) virus in human serum by using a combination of serologic assays. J Clin Microbiol. 1999;37:937-43.

10. Couzens L, Gao J, Westgeest K, Sandbulte M, Lugovtsev V, Fouchier R, et al. An optimized enzyme-linked lectin assay to measure influenza A virus neuraminidase inhibition antibody titers in human sera. J Virol Methods. 2014;210:7-14. http://dx.doi.org/ 10.1016/j.jviromet.2014.09.003

11. Hobson D, Curry RL, Beare AS, Ward-Gardner A. The role of serum haemagglutination-inhibiting antibody in protection against challenge infection with influenza $\mathrm{A} 2$ and $\mathrm{B}$ viruses. J Hyg (Lond). 1972;70:767-77. http://dx.doi.org/10.1017/ S0022172400022610

12. Hannoun C, Megas F, Piercy J. Immunogenicity and protective efficacy of influenza vaccination. Virus Res. 2004;103:133-8. http://dx.doi.org/10.1016/j.virusres.2004.02.025

13. Coudeville L, Bailleux F, Riche B, Megas F, Andre P, Ecochard R. Relationship between haemagglutination-inhibiting antibody titres and clinical protection against influenza: development and application of a bayesian random-effects model. BMC Med Res Methodol. 2010;10:18. http://dx.doi.org/10.1186/1471-2288-10-18 
14. Sridhar S, Begom S, Hoschler K, Bermingham A, Adamson W, Carman W, et al. Longevity and determinants of protective humoral immunity after pandemic influenza infection. Am J Respir Crit Care Med. 2015;191:325-32. http://dx.doi.org/10.1164/ rccm.201410-17980C

15. Kitphati R, Pooruk P, Lerdsamran H, Poosuwan S, Louisirirotchanakul S, Auewarakul P, et al. Kinetics and longevity of antibody response to influenza A H5N1 virus infection in humans. Clin Vaccine Immunol. 2009;16:978-81. http://dx.doi.org/10.1128/CVI.00062-09

16. Buchy P, Vong S, Chu S, Garcia JM, Hien TT, Hien VM, et al. Kinetics of neutralizing antibodies in patients naturally infected by H5N1 virus. PLoS One. 2010;5:e10864. http://dx.doi.org/10.1371/ journal.pone. 0010864

17. Bonduelle O, Carrat F, Luyt CE, Leport C, Mosnier A, Benhabiles N, et al. Characterization of pandemic influenza immune memory signature after vaccination or infection. J Clin Invest. 2014;124:3129-36. http://dx.doi.org/10.1172/JCI74565

18. Chen Z, Liu H, Lu J, Luo L, Li K, Liu Y, et al. Asymptomatic, mild, and severe influenza $\mathrm{A}(\mathrm{H} 7 \mathrm{~N} 9)$ virus infection in humans, Guangzhou, China. Emerg Infect Dis. 2014;20:1535-40. http://dx.doi.org/10.3201/eid2009.140424

19. Zeng X, Mai W, Shu B, Yi L, Lu J, Song T, et al. Mild influenza A/H7N9 infection among children in Guangdong Province. Pediatr Infect Dis J. 2015;34:104-7. http://dx.doi.org/10.1097/ INF.0000000000000492

20. Wang X, Jiang H, Wu P, Uyeki TM, Feng L, Lai S, et al. Epidemiology of avian influenza A H7N9 virus in human beings across five epidemics in mainland China, 2013-17: an epidemiological study of laboratory-confirmed case series. Lancet Infect Dis. 2017;17:822-32. http://dx.doi.org/10.1016/ S1473-3099(17)30323-7

21. Wang X, Fang S, Lu X, Xu C, Cowling BJ, Tang X, et al. Seroprevalence to avian influenza $A(H 7 N 9)$ virus among poultry workers and the general population in southern China: a longitudinal study. Clin Infect Dis. 2014;59:e76-83. http://dx.doi.org/10.1093/cid/ciu399

22. Yang P, Ma C, Cui S, Zhang D, Shi W, Pan Y, et al. Avian influenza $\mathrm{A}(\mathrm{H} 7 \mathrm{~N} 9)$ and $(\mathrm{H} 5 \mathrm{~N} 1)$ infections among poultry and swine workers and the general population in Beijing, China, 2013-2015. Sci Rep. 2016;6:33877. http://dx.doi.org/10.1038/srep33877

23. Yang S, Chen Y, Cui D, Yao H, Lou J, Huo Z, et al. Avian-origin influenza $\mathrm{A}(\mathrm{H} 7 \mathrm{~N} 9)$ infection in influenza $\mathrm{A}(\mathrm{H} 7 \mathrm{~N} 9)$-affected areas of China: a serological study. J Infect Dis. 2014;209:265-9. http://dx.doi.org/10.1093/infdis/jit430

24. Chen J, Ma J, White SK, Cao Z, Zhen Y, He S, et al. Live poultry market workers are susceptible to both avian and swine influenza viruses, Guangdong Province, China. Vet Microbiol. 2015;181:230-5. http://dx.doi.org/10.1016/j.vetmic.2015.09.016

25. Chen Z, Li K, Luo L, Lu E, Yuan J, Liu H, et al. Detection of avian influenza $\mathrm{A}(\mathrm{H} 7 \mathrm{~N} 9)$ virus from live poultry markets in Guangzhou, China: a surveillance report. PLoS One. 2014;9:e107266. http://dx.doi.org/10.1371/journal.pone.0107266

26. He F, Chen EF, Li FD, Wang XY, Wang XX, Lin JF. Human infection and environmental contamination with avian influenza A (H7N9) virus in Zhejiang Province, China: risk trend across the three waves of infection. BMC Public Health. 2015;15:931. http://dx.doi.org/10.1186/s12889-015-2278-0
27. Huang SY, Yang JR, Lin YJ, Yang CH, Cheng MC, Liu MT, et al. Serological comparison of antibodies to avian influenza viruses, subtypes $\mathrm{H} 5 \mathrm{~N} 2, \mathrm{H} 6 \mathrm{~N} 1, \mathrm{H} 7 \mathrm{~N} 3$, and $\mathrm{H} 7 \mathrm{~N} 9$ between poultry workers and non-poultry workers in Taiwan in 2012. Epidemiol Infect. 2015;143:2965-74. http://dx.doi.org/10.1017/S0950268815000394

28. Xiang N, Bai T, Kang K, Yuan H, Zhou S, Ren R, et al. Seroepidemiologic study of influenza A(H7N9) infection among exposed populations, China 2013-2014. Influenza Other Respi Viruses. 2017;11:170-6. http://dx.doi.org/10.1111/irv.12435

29. Xu W, Lu L, Shen B, Li J, Xu J, Jiang S. Serological investigation of subclinical influenza $\mathrm{A}(\mathrm{H} 7 \mathrm{H} 9)$ infection among healthcare and non-healthcare workers in Zhejiang Province, China. Clin Infect Dis. 2013;57:919-21. http://dx.doi.org/10.1093/cid/cit396

30. Morens DM. Editorial commentary: pandemic H5N1: receding risk or coming catastrophe? Clin Infect Dis. 2013;56:1213-5. http://dx.doi.org/10.1093/cid/cit051

31. Koopmans M, Wilbrink B, Conyn M, Natrop G, van der Nat H, Vennema H, et al. Transmission of H7N7 avian influenza A virus to human beings during a large outbreak in commercial poultry farms in the Netherlands. Lancet. 2004;363:587-93. http://dx.doi.org/10.1016/S0140-6736(04)15589-X

32. Du Ry van Beest Holle M, Meijer A, Koopmans M, de Jager CM. Human-to-human transmission of avian influenza A/H7N7, the Netherlands, 2003. Euro Surveill. 2005;10:264-8. http://dx.doi.org/10.2807/esm.10.12.00584-en

33. Meijer A, Bosman A, van de Kamp EE, Wilbrink B, Du Ry van Beest Holle M, Koopmans M. Measurement of antibodies to avian influenza virus $\mathrm{A}(\mathrm{H} 7 \mathrm{~N} 7)$ in humans by hemagglutination inhibition test. J Virol Methods. 2006; 132:113-20. http://dx.doi.org/10.1016/j.jviromet.2005.10.001

34. Couch RB, Decker WK, Utama B, Atmar RL, Niño D, Feng JQ, et al. Evaluations for in vitro correlates of immunogenicity of inactivated influenza a $\mathrm{H} 5, \mathrm{H} 7$ and $\mathrm{H} 9$ vaccines in humans. PLoS One. 2012;7:e50830. http://dx.doi.org/10.1371/ journal.pone. 0050830

35. Hung IF, To KK, Lee CK, Lee KL, Chan K, Yan WW, et al. Convalescent plasma treatment reduced mortality in patients with severe pandemic influenza A (H1N1) 2009 virus infection. Clin Infect Dis. 2011;52:447-56. http://dx.doi.org/10.1093/cid/ciq106

36. Zhou B, Zhong N, Guan Y. Treatment with convalescent plasma for influenza A (H5N1) infection. N Engl J Med. 2007;357:1450-1. http://dx.doi.org/10.1056/NEJMc070359

37. Wu XX, Gao HN, Wu HB, Peng XM, Ou HL, Li LJ. Successful treatment of avian-origin influenza A (H7N9) infection using convalescent plasma. Int J Infect Dis. 2015;41:3-5. http://dx.doi.org/10.1016/j.ijid.2015.10.009

Address for correspondence: Wu-Chun Cao or Li-Qun Fang, State Key Laboratory of Pathogen and Biosecurity, Beijing Institute of Microbiology and Epidemiology, 20 Dongdajie, Beijing 100071, China; email: caowc@bmi.ac.cn or Fang_1q@163.com; Li-Ling Chen, Department of Infectious Diseases, Suzhou Municipal Center for Disease Control and Prevention, No. 72 Sanxiang Rd, Suzhou City, Jiangsu Province, China; email: liling_chen@163.com 